\title{
Safety of Dams: A Pathological Approach of Qualitative and Quantitative Risks
}

\author{
Flavio Augusto Settimi Sohler ${ }^{1,2}$ and Laura Maria Mello Saraiva Caldeira ${ }^{3}$ \\ 1. National Civil Engineering Laboratory-LNEC, Eletroras Furnas, Aparecida de Goiannia 74923-650, Brazil \\ 2. National Council of Scientific Research-CNPq, Brasilia 71605-001, Brazil \\ 3. National Civil Engineering Laboratory - LNEC, Geotechnics Department, Lisbon, 1700-066, Portugal
}

\begin{abstract}
Dams are critical and essential elements in any infrastructure and, in front of accidents occurred in many countries, it is extremely important to know the risk of these structures. Inserted in this context, it was found in the technical literature, methods and tools capable of measuring the exposure value by means of indicators. In the study, the highlights were 12 methods of qualitative, semiquantitative and quantitative risk analysis, representing an overview of risk analysis methods available in the literature with potential use in dams, that it has been done into electronic spreadsheets. The case study is performed on a sample of concrete dam and earth/rockfill built and operated by Eletrobrás Furnas Company, supported by documentary research, projects, field inspections and interviews with experts. After applying the methods and the analysis thereof, has been prepared the Eletrobras Furnas dam risk analysis method which is characterized by adapting the criteria analyzed to the reality of the company's dams and it was also performed the portfolio risk analysis of 18 dams. In spite of the variety and subjectivity of qualitative and semiquantitative methods, the results show that they tend to converge on the analysis of dam based on risk. The application methodology demonstrates the feasibility assessment stage, covering the preliminary analysis for portfolio dams, followed by formal and individual risk analyzes for the most critical structures. These results confirm the applicability of risk analysis techniques, contributing to the consolidation of this tool as fundamental in the dam safety.
\end{abstract}

Key words: Dam safety, dams breaks, methods and tools for risk analysis, risk analysis in dam portfolio.

\section{Introduction}

The dams since the beginning of human history were fundamental to development. Its construction was, above all, the scarcity of water in the dry season and the consequent need for water storage [1]. The dams are among the most important achievements of the man, going beyond generally other types of buildings, both in volume and cost, as in social importance and at risk. So, they require the most advanced methods of construction and design. The development of new materials, the refinement of the dam project and the study of the best calculation criteria and of best construction methods have always been object of investigation and permanent efforts, in order to make the safest and most economical dams [2].

Corresponding author: Flavio Augusto Settimi Sohler, $\mathrm{Ph} . \mathrm{D}$., research field: civil engineering.
The dams play their roles, whether for human or animal supply, irrigation and power generation, operating, sometimes for many years. However, despite the dam engineering has progressed enough, people are often surprised by news of breakages and accidents, which cause financial, environmental and social impacts.

According to studies carried out worldwide [3], until 1980, about 200 dams went into break with catastrophic consequences, having occurred more than 8,000 deaths in such disasters.

That way, the prevention of accidents should extend, from initial studies and projects, until its deactivation, and also the construction and operation phases. Is knowledge of good technique that, before there was an accident, the dam, as "living" structure, always signals their weaknesses, either by visual signals, such as cracks and leaks, or by signs that need to be performed by qualified technicians, as, for example, moves and 
variations of pressure, enough?

The breaking of a dam is an event that can occur due to different causes. The evaluation of potential impacts is a preventive procedure that is part of the responsibility of the owner. This analysis must define the possible consequences of the breaking of the dam and preventative measures to mitigate the potential consequences. The possibility of rupture of a dam is a source of risk to the population, to the economy and to the potentials of the valley downstream.

Upon the importance of the construction of dams for the world stage and the complexity of this type of construction, which usually involves several areas of engineering, this article aims to identify the main risks to dams, searching methodologies based on risk analysis able to sort a set of dams according to the risk that provides the environment in which they are installed by establishing a method of risk analysis to be employed within the company.

Lessons learned from dam breaks have revealed that a long period of normal operation is no guarantee of future conditions of security, since there have been cases of sudden rupture after 10 and 20 years of normal operation.

With the advance in the understanding of the hydrologic and hydraulic phenomena, the technology associated with the process of construction and regulatory standards ensured a greater safety throughout the useful life of a dam. However, the perception of risk related to disasters also evolved, due to public demand for higher standards of safety and evaluation of risk studies [4].

Notice that several security levels can be associated with a dam at every stage of life: design, construction and operation. According to Viseu and Martins [5], it should be pointed out that it is not possible to achieve a level of $100 \%$ security. The level of security that should achieve depends basically on the number of human lives that may be lost in the case of a critical event. Another limit relates to the cost of each work and the human and material resources that can be made available to the security tasks.

The increasing development and the increase of population densities in areas downstream of dams lead to an increasing need to be aware of and to prevent exposure of the population to unacceptable levels of risk. In this way, the acceptable level of risk will tend to be analyzed by an increasing number of people and, as a result, the requirements in terms of security will tend to increase in the future.

The ICOLD (International Commission on Large Dams) [6] emphasizes that the formal risk assessment for dams, using recognized methods of risk analysis, is in the development stage and more research and discussions are required. The theme of this article encourages the continuation of this discussion on the applicability of risk analyses within the dam safety management.

In addition, the risk analysis process, by itself, brings numerous advantages to the decision maker. Caldeira [7] points out that the risk analysis, as a structured decision support process, provides a consistent technique of comparing the relative safety of structures, allowing establish priorities with a view to increasing the structural safety. Hartford and Baecher [8] point out that the risk analysis techniques improve the traditional process, providing, among several benefits, a broad and integrated analysis of all components of the system and how they interact with each other.

Therefore, before the great potential for application of risk analysis in dams, this work can be considered of great importance, contributing to the consolidation of the tools in the field of risk management and safety of dams.

The overall objective of this article is the application, analysis and discussion of risk analysis techniques in concrete and embankment dams, including preliminary risk analysis methods for portfolio of dams and formal risk analysis methods in dams.

\section{Risk and Failure of Dam}

Risk is the possibility of undesirable occurrences 
and cause damage to the population, economic systems and the environment. The failure of a dam, among others, can be the spontaneous flow of water resulting from an improper operation or the rupture of a structure. A failure can cause downstream flooding, the damage to lives and property, forcing people to evacuate the places where they live. So, they make the whole life of the society in that place difficult. Harrington [9] presents the main sources of faults in embankment dam: overtopping (38\%), massive leak and in the pipes (33\%), defects in the foundations $(23 \%)$ and others (6\%).

In a survey conducted by the ICOLD [3], about the major accidents in concrete dams, it was concluded that most happened by problems with the foundation (69\%), body of the dam (16\%) and the dam body and foundation (15\%). The main causes in the foundation, were lack of hydraulic resistance (66\%), lack of resistance to cutting (17\%) and unsuitability for the work designed (17\%). The main causes in the body of the dam were inadequate forms of dam and its insertion in the valley $(72 \%)$ and lack of concrete tensile strength $(28 \%)$. The main failure of the dam body and foundation were lack of mechanical resistance of the foundation or inadequacy of structural shapes.

The break, generally speaking, is the loss of capacity of a dam, or part of it, working as intended [10]. More specifically, in concrete and masonry dams, the loss of mechanical strength or hydraulic resistance of the foundation, is the cause of major accidents and incidents. The loss of connection with the foundation in the amount of foot concrete dams, particularly vaults, is relatively frequent, because the hydrostatic pressure induces the vertical traction pressures in the upstream foot and in the massive of the foundation that is adjacent [11].

In earth dams, the main cause of the ruptures, is related to soils that are the most vulnerable materials in relation to the overtopping. Internal erosion and flow concentration in the body of the dam and in contact with rigid structures or the foundation, is another important factor in the deterioration. Other aspects to consider are the excessive settlements of crest, due to inadequate characterization of deformation of materials and landslides of the slopes, especially to neutral tensions for faulty drainage system. Another important point of cause of breakage is the use of poor-quality landfill materials like soil-mixes rock and liquefaction problems on foundations of sand or silt soil in the event of earthquakes. For the rock fill, dams include the deterioration that occurred due to internal erosion, whether on the foundation or in the body of the dam. Also, the number of cases of excessive percolation through the upstream curtains is significant.

Therefore, considering all the steps of a dam (design, construction and operation), and mainly in order to meet the relevant legislation regarding the reporting of safety of dams, the evaluation as to the risks of dams involves necessarily the steps outlined in Fig. 1.

The minimum requirements for a safety assessment can be divided in the steps shown in Fig. 2.

\section{Risk Management Process}

Risk can be used in various fields of knowledge, being a condition with the potential to generate a damage, that is, a dangerous condition with character of uncertainty [12-14]. This adaptation must be used, because it is considered that a dam is not exposed to a risk, but a dangerous condition, since, in the context of the risk assessment, the risk, in fact, is estimated, considering the probability and consequence. Another possible approach is in process of identifying risks, which represents the determination of what can go wrong, why and how. In this case, the process involves the recognition of hazards (or initiators) to which the dam is exposed, the failure modes, responses and results in systems and subsystems, exposure factors and the resulting adverse consequences [7, 10, 15]. Fig. 3 illustrates the process.

However, as with its terminology, it appears in the literature that there is no unified classification about the dangers associated with dams. In addition to being the 


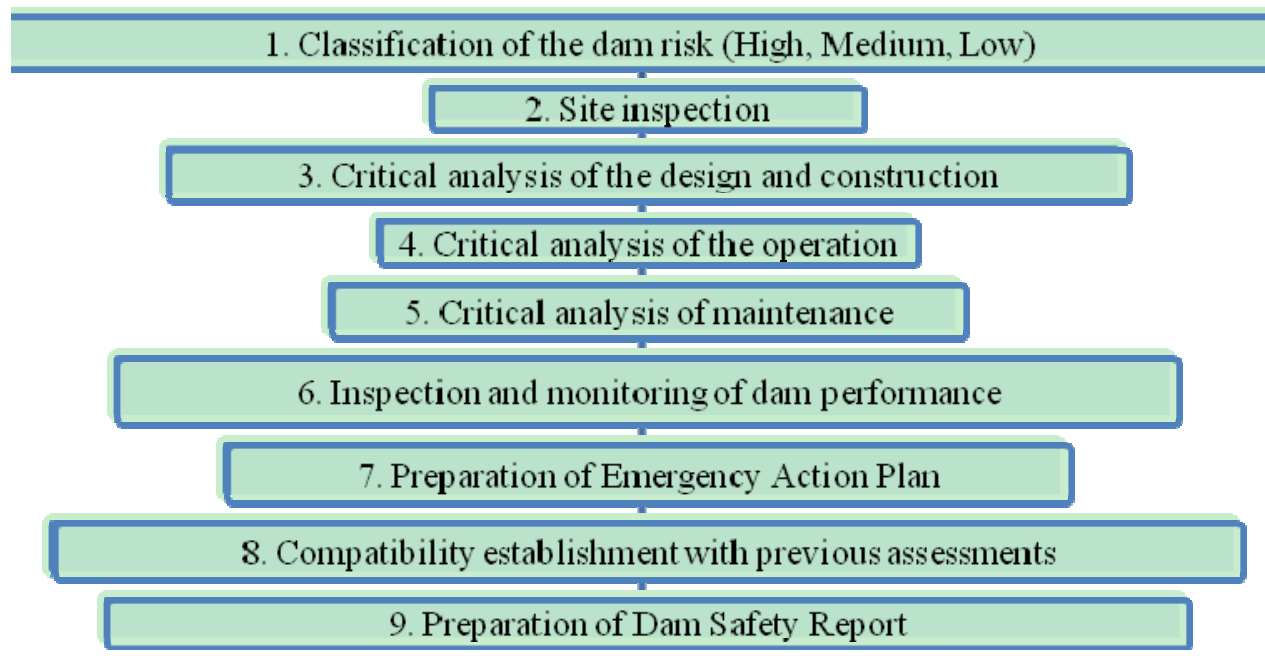

Fig. 1 Steps to risk assessment in dams.

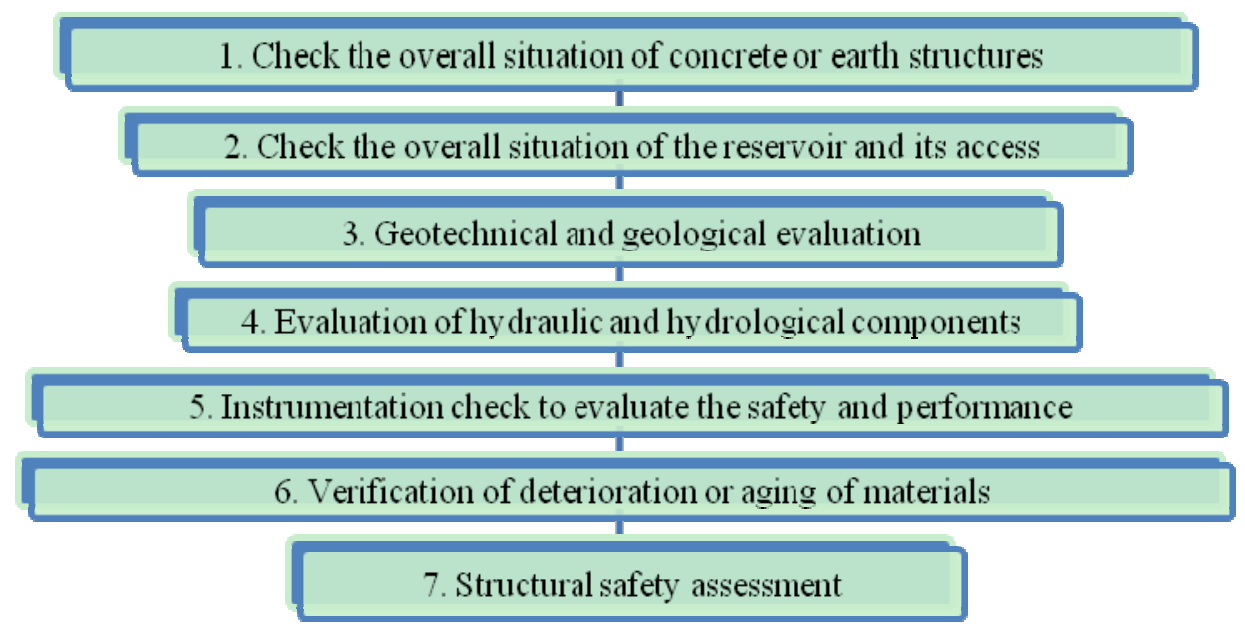

Fig. 2 Minimum requirements for a safety evaluation of dams.

\begin{tabular}{|c|c|c|c|c|}
\hline \multicolumn{4}{|c|}{ FAILURE SCENARIO } & \\
\hline $\begin{array}{l}\text { Hazards: } \\
\text {. Flood } \\
\text {. Seism } \\
\text {. Internal Failure }\end{array}$ & $\begin{array}{l}\text { System response: } \\
\text {. Overtopping } \\
\text {. Deformation } \\
\text {. Slope instability } \\
\text {. Internal erosion }\end{array}$ & $\begin{array}{l}\text { Result: } \\
\text { Breach in } \\
\text { the dam }\end{array}$ & $\begin{array}{l}\text { Exposure factors: } \\
\text {. Season of the year } \\
\text {. Warning time } \\
\text {. Time of day }\end{array}$ & $\begin{array}{l}\text { Consequences: } \\
\text {. Loss of lives } \\
\text {. Economic } \\
\text {. Emvironmental } \\
\text {. Social }\end{array}$ \\
\hline
\end{tabular}

Fig. 3 Risk identification process (adapted from Bowles [15]).

most varied possible, they are grouped together and listed in different ways and natures, being common to find references with dubious failure modes and system responses. Proper classification of hazards should be logic, allowing expansion and subdivisions, if necessary.

The criteria for acceptability and tolerability represent the maximum permissible limits for the risk.
Its terminology, widely accepted today, is set by the Health \& Safety Executive [16]. The acceptability of the individual risk of rupture in dams in the United Kingdom, is $10^{-6}[17]$ and in Australia is $10^{-8}[18]$ per person per year.

According to the HSE [16], the unacceptable area represents a region where its risks, whatever the level of benefits associated with the activity, is unacceptable. 
The acceptable zone represents risks considered insignificant and adequately controlled. The intermediate zone between the previous two, is considered a tolerable region, whose risks are, typically, of activities to which the population is prepared to tolerate in exchange for the guarantee of benefits. In this case, the residual risks should be kept as low as reasonably practicable, determined by principle ALARP (as low as reasonably practicable). The ICOLD [6] maintains that the risk tolerance differs for each country, because it depends on the cultural issue.

There are various methods of risk analysis, available in specialized literature, which best suit the dams, and each one has its advantages and disadvantages. The conclusion is that there is no single method for all situations. Depending on the specific interest, you can apply one or more methods that complement each other.

The inspection method [19], confidence index and downstream impact of the enterprise [17] and HAZOP (hazard and operability analysis) are methods based on visible anomalies. The risk index methods [20], risk potential [21], behavior index of dam [22], risk class [23], risk category and its associated potential damage [24] and modified global risk index (referenced by Pimenta [25]) are methods for risk analysis in portfolios of dams. The FMEA (analysis of failure modes and their effects) and FMECA (analysis of failure modes, effects and criticality) aims to identify functions, through the causes and consequences of a hazard and their mitigation modes. Finally, the method of ETA (event tree analysis) has the objective of identifying the event initiator and its consequences chained.

The methods have been automated via MS-Excel spreadsheets with the objective of implementation in two hydroelectric power plants defined in case study of this work.

As reported by ICOLD [6], there are a variety of classifications, established by procedures and well-defined criteria. The criteria related to different characteristics of the structure, as well as the magnitude of the consequences, are highly variable and depend on the authors, owners, companies or existing regulations.

\section{Methodology}

This article aims to define risk analysis methodology for dams to the solution of a particular problem (risk assessment of dam) in the context of risk management and safety of dams. It is also featured as a case study, since the application focuses on a group of the company's dams Eletrobrás Furnas Centrais Elétricas.

The criteria judged as representative for the definition of the sample in this study were hydropower dams and dam classification as high. Thus, two dams were selected, a concrete gravity and embankment dam, which were applied various methods of risk analysis. Risk analysis of the portfolio was held in 18 dams of the Eletrobrás Furnas, and applied the method of risk analysis for dams developed for the company.

For data collection, documentary researches were used as project analysis and technical reports of the dams, content analysis, field inspections on dams and verification of reports and results, in-depth interviews with the professionals who worked during the construction of the dams and those who currently work in the maintenance, conservation and operation. The interviewees were the employees of construction, projects, environmental engineering, studies and feasibility departments.

For applications of the methods in the dams of the company, it was first carried out an analysis in the portfolio of dams and then to those considered in the first stage as higher risk, and finally, carried out a more detailed and specific analysis. This idea is also shared by Bowles [27], through the portfolio risk assessment. In order to analyze the risks of dams, the methods presented in Fig. 4 were used, which illustrate the general scheme of the study.

First was held the portfolio risk analysis of dams, and of these, two hydroelectric power plants were 


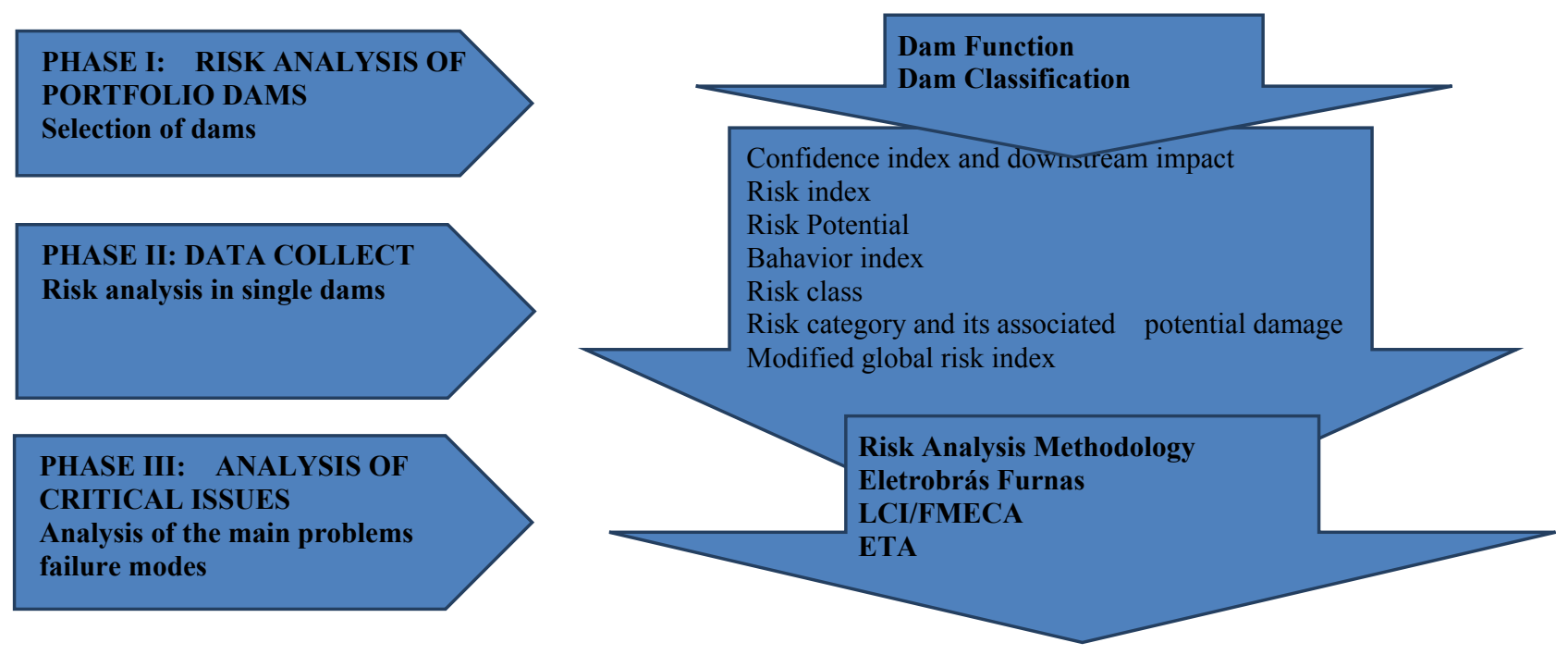

Fig. 4 General scheme of the methodology used in this study.

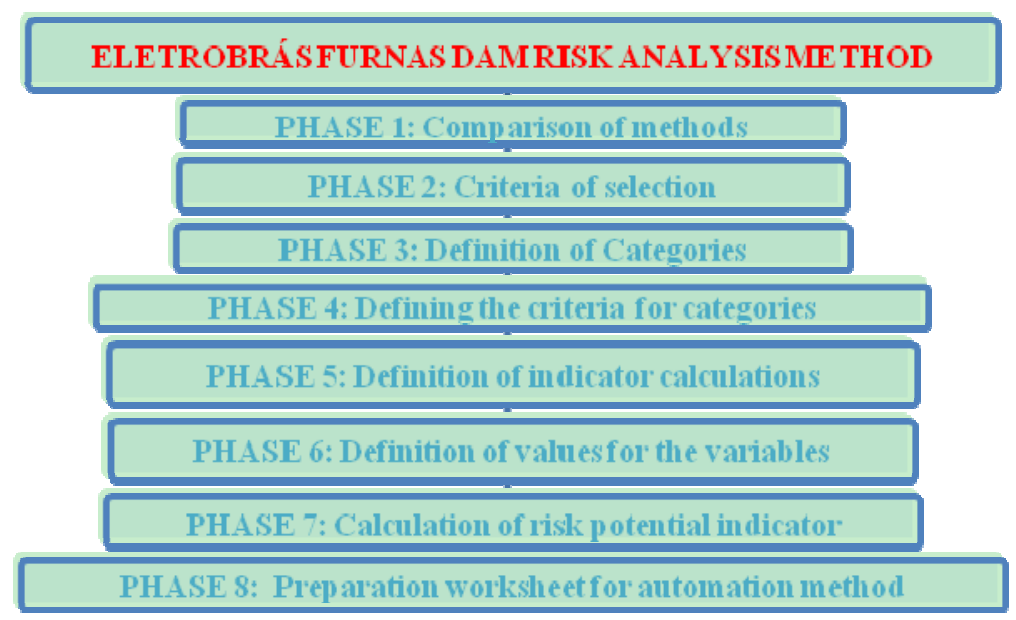

Fig. 5 Process of elaboration of the dam risk analysis method.

selected: Simplício-Queda Única and Batalha.

Simplício was built in the Paraíba do Sul river, on the border of the States of Minas Gerais and Rio de Janeiro. This hydroelectric power plant has 305.7 MW of power capacity and the works were completed in 2013. Batalha, in São Marcos river, between the States of Goiás and Minas Gerais, had his works completed in 2014 and has $52.5 \mathrm{MW}$ of power capacity.

Based on the mentioned methodologies, a method came up that took into account the main previous criteria, including the criteria required by law in Brazil, about security of dams, and that also took into account the particular characteristics of the company's dams. Fig. 5 presents the process of elaboration of the method: first was identified the criteria that will be included in the method, establishing three categories: DP (danger potential), to measure aspects of construction; $P V$ (potential vulnerability), to measure the results of the inspections on the dam; PI (potential impact), to measure the social, economic and environmental downstream impact, in case of rupture of the dam.

The $P R$ (potential risk) is calculated by the equation:

$$
P R=(D P+P V) \times P I
$$

Two scales were set: one for dealing with the risks of construction and inspection $(D P$ and $P V)$ and another to dealing downstream risks $(P I)$. The scale $(D P+P V)$ was divided into three classes: A $(D P+P V \geq 47)$, meaning that there may be structural problem; $\mathrm{B}(30 \leq$ 
$D P+P V \leq 46)$, meaning that there may be some points to improve; $\mathrm{C}(D P+P V \leq 29)$, meaning that can be done only routine inspection. The $P I$ range was also divided in three classes: A ( $P I \geq 37)$, meaning that inspections should be conducted at a lower frequency, 1 month to 6 months, since the downstream damage can be high; $\mathrm{B}(23 \leq P I \leq 36)$, meaning you can perform annual inspections; $\mathrm{C}(P I \leq 22)$, meaning that it can be carried out inspections every 2 years.

The Eletrobrás Furnas dam risk analysis method was applied in 18 of the company's dams. The application took place by sending and filling the spreadsheets by experts, as well as the analysis of the technical data sheets of dams and of the dam safety analysis.

It was found that the structural aspect and safety of dams, all are Class $\mathrm{C}$, which denotes that the techniques and methods of security is effective. It was also verified that the economic, social and environmental impacts, in case of rupture of the dams, can be catastrophic, meaning that they should always monitor the dams periodically, and maintain a continuous modernization planning of hydroelectric power plants.

\section{Results}

First, the Eletrobrás Furnas risk analysis method was used to check which class of risks that the dams of Simplicio and Batalha are classified in relation to the defined criteria. In addition to this method, the detailed methods were also applied in Fig. 4. Then, the LCI (location-cause-indicator), FMECA and ETA for more detailed risk analysis of the enterprises were used.

The results of applying the method developed to Eletrobrás Furnasis were consistent with other methods applied in the same dams.

\subsection{Application of LCI Method}

The first stage on the impact assessment was intended to calculate the OII (overall impact index), which is segmented into two categories: valley downstream until $5 \mathrm{~km}$ and from $5 \mathrm{~km}$ to $30 \mathrm{~km}$.

The $O I I$ of Simpliciodam was calculated as $O I I=$
$7,050.75$ and of Batalha dam as 126.02 .

The second stage of the method deals only the definition of subsequent studies, according to the results obtained in the $O I I$.

As expected, the Simplicio dam is classified with high impact $(O I I>750)$, requiring the evaluation through the LCI diagram. The Batalha dam has $O I I<$ 175, and so, has low risk, requiring no subsequent studies.

For the Simplicio dam, the risks that have stood out in the locations "massive dam, foundation and shoulder pads-SQ1", "adduction and discharge structures-SQ2 and SQ3" and "spillways and their components-SQ4 and SQ5" are listed in Table 1. The columns "ID (identification)" of the tables represent only a suggested ID for the elements (SQ-Simplicio-Queda and BA-Batalha), to facilitate their placement in the risk matrix.

For the Batalha dam, the risks that have stood out in the locations "spillways and their components-BA1, BA2 and BA4" and "adduction and discharge structures-BA3 and BA5" are listed in Table 2. In the "massive dam, foundation and shoulder pads" location, the risks were smaller.

In the case of the Simplicio dam, the most critical elements are related to the deformation/cracks, percolation and corrosion, observed through the dam and foundations, as well as the adduction and discharge structures, being interrelated. The criticality and the higher risk index and ordering index of the first two elements reflect the probability of higher occurrence of anomalies (indicators currently observed in the field). On the other hand, the low level of $C F$ (confidence level) shows the knowledge of the experts about the issues under review and, therefore, greater ease in the estimation of indicators, based on studies already carried out, existing data, visual inspections and analysis instrumentation. In Tables 1 and $2, I_{O}$ means sort index, $I_{C}$ means criticality index, $I_{R}$ means risk index and $C F$ means confidence level.

In Batalha dam, the indicators suggest that the most 
Table1 Critical elements in Simplício dam.

\begin{tabular}{llllll}
\hline ID & Critical elements & $C F$ & $I_{O}$ & $I_{C}$ & $I_{R}$ \\
\hline SQ1 & Deformations and cracks caused by instability & 2 & 12 & 24 & 169,218 \\
SQ2 & Corrosion caused by damaged pipes & 2 & 12 & 24 & 169,218 \\
SQ3 & Percolation and infiltration caused by damaged pipes & 2 & 10 & 20 & 141,015 \\
SQ4 & Rapid lowering of the reservoir caused by flaws in locks & 2 & 6 & 12 & 84,609 \\
SQ5 & Damage to the structures caused by obstruction of flow & 1 & 10 & 10 & 70,508 \\
\hline
\end{tabular}

Table2 Critical elements in Batalha dam.

\begin{tabular}{llllll}
\hline ID & Critical elements & $C F$ & $I_{O}$ & $I_{C}$ & $I_{R}$ \\
\hline BA1 & Damage to the structures caused by obstruction of flow & 2 & 9 & 18 & 2,268 \\
BA2 & Located damage caused by inadequate capacity & 2 & 8 & 16 & 2,016 \\
BA3 & Surface movement caused by auxiliary structures & 2 & 8 & 16 & 2,016 \\
BA4 & Percolation and infiltration & 2 & 6 & 12 & 1,512 \\
BA5 & Percolation and infiltration caused by auxiliary structures & 1 & 9 & 9 & 1,134 \\
\hline
\end{tabular}

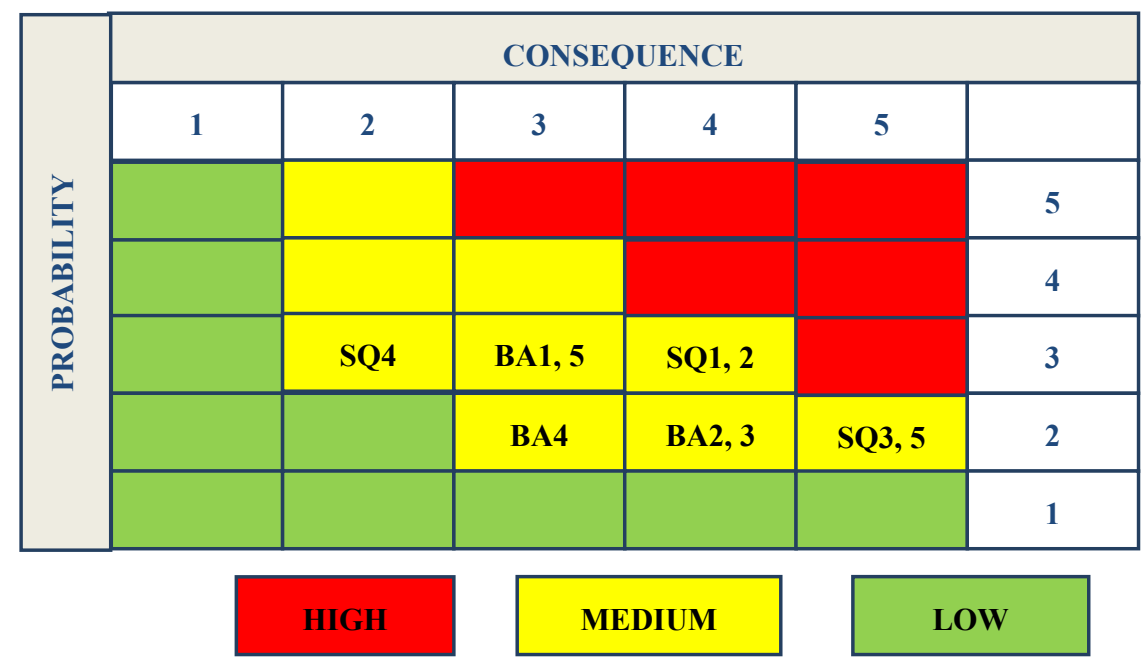

Fig. 6 Risk matrix of the LCI method for Simplicio and Batalha dams.

critical elements are related to possible project deficiency concerning about the flow and inadequate capacity of spillways and their components. The probability of failure of the elements associated with the cause "obstruction of flow" is higher to the cause "inappropriate capacity", since in the first, the repressions of occurrences are real and more easily detected.

When comparing the risk index of the two dams, it was concluded that Simplicio dam has higher risks than Batalha dam. This is due to the higher numbers in the "consequence" to the indicators related to percolation/piping, these values specifically pre-set in the method. That is reasonable, considering that these indicators, percolation, surges and piping, according to statistics from ruptured dams, are more harmful to the safety of dams than the manifestation of deformations and cracks in structures.

The risk matrix for Simplicio and Batalha dams, with the qualitative description of probability and consequence is shown in Fig. 6, with the critical elements (SQ1, SQ2, SQ3, SQ4 and SQ5) and (BA1, BA2, BA3, BA4 and BA5) of dams represented, with high confidence level (2), enabling faster detection and control.

\subsection{Application of FMECA Method}

In view of the variety of existing tables in the 
literature for implementing the method, was adopted the table layout based on the recent work of Portes [28] and Esposito and Palmier [29] and comprising the items usually adopted in the methodology.

\subsubsection{Simplicio Dam System}

The most important items are the components of the subsystem of the foundation and the subsystem of shoulder pads. In the first case, the failures are related to the foundation, with the internal erosion failure modes (2(2) and 2(4)), the excessive percolation (2(3)) and the mass movement (2(1)). The severities for the final effects, global instability (mass movement) and piping (internal erosion) are slightly different. It was considered that the consequences of the piping, as being a progressive phenomenon, can be minimally mitigated due to the time factor, as for example, decreasing of water in reservoir, unlike a break by collapse of foundation (global instability). The causes of remote occurrence are related to deficient or inadequate foundation treatments, geological singularities not detected and excessive percolation associated directly to geotechnical conditions of the foundation. Detection was considered moderately high, because, just as in the previous case, despite the failure mechanisms are internal, they can be indirectly identified by visual inspections and instrumentation installed in the foundation and downstream areas, besides the possibility to perform the reinforcement of foundation treatment by injection or drainage.

In the second case, the components of the subsystem shoulder pads have as failure mode or dysfunction, basically the mass movement (3(1), 3.1(1) and 3.2(1)) and internal erosion (3(2), 3.1(2) and 3.2(2)). The high value of severity (impact) is related to the overall instability of the dam with the eventual rupture of the shoulder pads and the consequences resulting from the breach. The causes are related to design or construction failures, in the contact of shoulder pads with the dam, creating preferential paths of percolation. These possible causes were judged as being of remote occurrence, according to field evidence, instrumentation and investigations performed. Detection was considered high, because, despite the failure mechanisms are internal, they can be indirectly identified by monthly visual inspections and, mainly, by the instrumentation (piezometric) installed in the dam.

\subsubsection{Batalha Dam System}

The most important elements are located in the dam system components and of upstream rockfill subsystem. In the first case, the failures are related to the dam, with failure mode the mass movement (1(2)). The severities for the final effects, global instability with uncontrolled release of water were considered serious. The causes of remote occurrence are related to the exceptional loads. Detection was considered high, because, despite the failure mechanisms are internal, they can be indirectly identified by visual inspections and instrumentation installed in the foundation and downstream areas, besides the possibility to perform the decreasing of water in the reservoir, as mitigation measure.

In the second case, the elements of upstream rockfill subsystem have as failure mode basically the excessive deformation (dysfunction) by mass movement (1.3(2)).

The high value of severity (impact) is related to cracking with local or global instability of the dam and overtopping possibility, with the eventual opening of breach and possible rupture of the dam. The causes may be related to fluency materials, constructive inadequacy by poor compression or inadequacy of project by inadequate materials properties. These possible causes were judged as being of remote occurrence, according to field evidence, instrumentation and investigations performed. Detection was considered high, as it was described to Simplicio dam.

The criticality, by the homogeneity detection score, tends to converge with the most critical values of the RPN (risk priority number). The risk matrix suggested in Fig. 7 presents the criticality of the most important failure modes. The criticality of Simplicio dam is located in the quadrants 1-VI and 2-VI and Batalha dam 


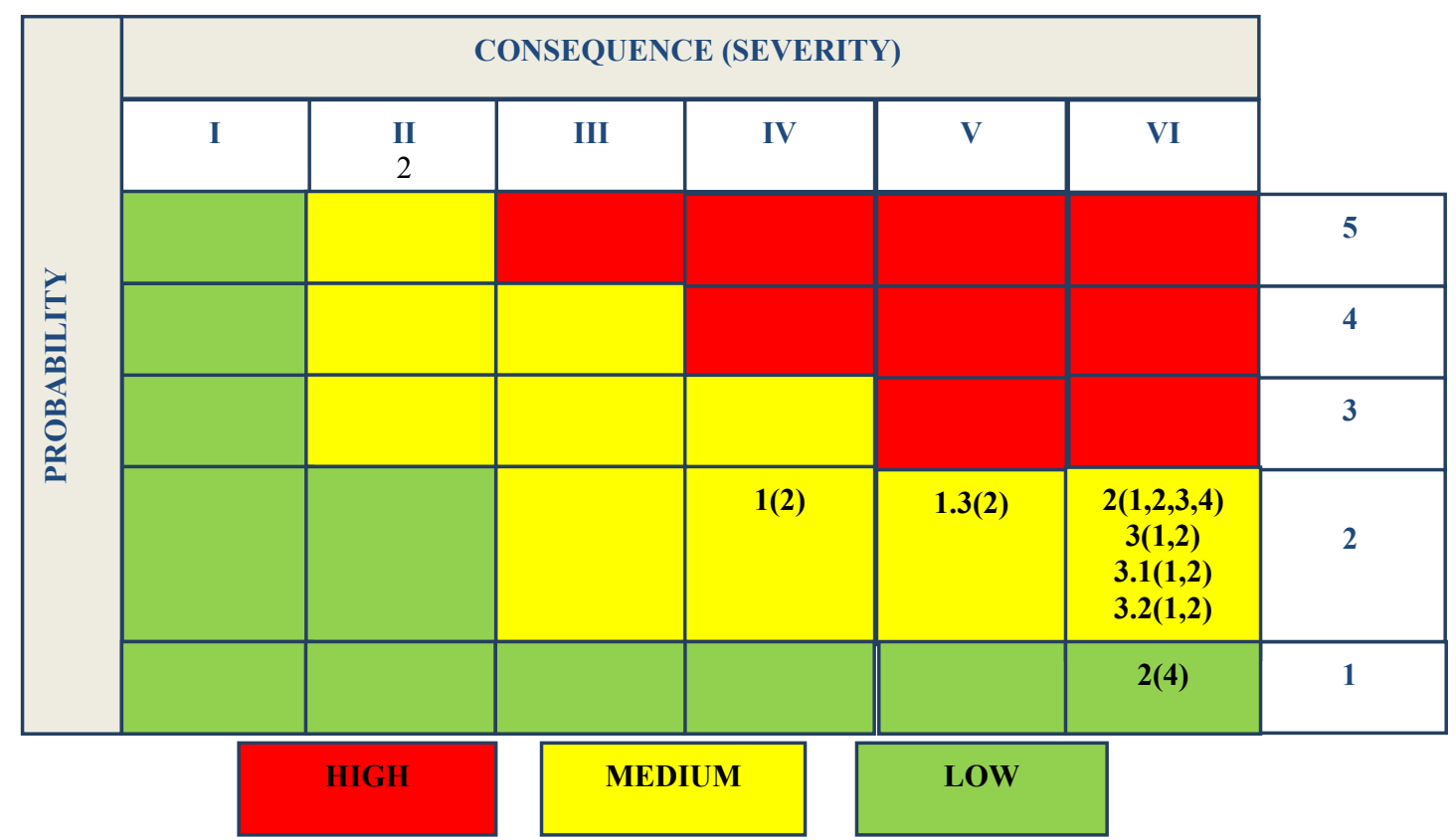

Fig. 7 Risk matrix for the critical elements of the Simplício and Batalha dams.

in the quadrants 2-IV and 2-V.

The results, based on the discussion of the previous methods, confirm and detail the most critical break modes in two dams, demonstrating the effectiveness of the method applied. The methodology of the FMECA also confirmed the alignment with the results of the previous method LCI. The risk matrix, however, presents few differences in relation to the LCI, because of the different concepts used in the consequence component and the different classes considered in the occurrence or probability index. However, the overall result of the two methods, FMECA and LCI, was similar among themselves, because the failure modes are located in middle or moderate region of the risk matrix.

It is important to note that the range of values of the probability (in percentage), mainly associated with the cause, does not represent a direct correlation with the probability of dam rupture. In probabilistic terms, really the probability of rupture of dams, such as those analyzed, are certainly lower than what would be considered "unlikely" (= class I $<0.1 \%$ ).

It appears from the practical application of FMECA in dams, that this method is preventive and logical, as well as become a quick reference for troubleshooting. The methodology enables structured knowledge of the system of dams, with consideration of the functionality, failure modes, causes and consequences of each subsystem or component, in anticipation of the measures of prevention and detection.

Preliminary analysis of risk for dams portfolio through risk index and classification matrix, although simple and subjective, allow a quick classification of structures based on risk. Despite some differences between the methods used, it was found that there is a clear convergence in various classification systems for the sample of selected dams.

\section{Application of the ETA}

In some cases, the statistics of failure are not sufficient for determining the reliability of the application to each dam in an absolute sense [30]. In this way, to this work, the probability of rupture of dams is presented within a relative ranking.

Noting that in the United Kingdom the acceptability of risk at the individual level in rupture of dams, is around $10^{-6}[17]$ and in Australia is around $10^{-8}$ [18] per person per year, it was defined inTable 3 . In this way, it 
Table 3 Rupture of dam level of acceptability.

\begin{tabular}{ll}
\hline Annual probability of rupture (per person per year) & Risk assessment \\
\hline $10^{-4}$ & Very worrying \\
$10^{-5}$ & Worrying \\
$10^{-6}$ & Acceptable \\
$10^{-7}$ & Good performance \\
$10^{-8}$ & Great performance \\
\hline
\end{tabular}

is considered the acceptable value of $10^{-6} /$ person year, with lower values being considered of good performance and higher values somewhat worrisome.

After defining the acceptability level, it proceeded to the determination of the most critical scenarios in terms of security, which could, according to the geological and geotechnical features, hydrological conditions and the type of dam history, lead eventually to rupture. Within these scenarios, the analysis focused on the following key events: slipping through the rock-concrete interface; overtopping; internal erosion through soil-concrete interface; internal erosion by the foundation and disruption of pipeline corrosion. The possibility of overtopping was analyzed, both as a result of a hydrological risk, caused by a decamilenar flood, or due to the maximum flood likely, as well as due to a slipping slope in the area of the reservoir. The slipping through the foundation was considered on the basis of the analysis of stability of concrete structures, where the factors of security by slipping were more critical.

It was also simulated the possibility of erosion of the dam by overtopping, and as a result the break by opening the breach. The possibility of internal erosion (piping) was simulated by opening of the breach, for the case of soil-concrete interface. Internal erosion through the foundation was simulated as a shape of a tube by the foundation, sometimes progressing eventually to the formation of a breach, reaching the crest of the dam. In this way, two alternatives were simulated for the preparation of the event tree. In the first alternative, assumed a worst-case scenario, where were incorporated into uncertainty with respect to the treatment of the foundation, to the quality control of the compacted embankment, to the exact dimensions of the internal drainage system of the dam and foundations, to the reliability of a monitoring plan, in order to provide an alternative representing higher risks. In the second alternative, a more optimistic scenario was simulated, with a good implementation of structures and good treatment of foundations in terms of deformability, resistance and permeability, as well as a good instrumentation and monitoring plan with routine inspections.

\subsection{Event Tree for Overtopping}

In Figs. 8 (Event Tree I) and 9 (Event Tree II), the event trees prepared for the simulation of a possible overtopping are represented, where the concrete structures would resist without major problems to overtopping, since they are supported on gneissic rock of good consistency, while the massive landfill, could suffer serious erosion and eventually breaks depending on the thickness of the water depth and time overtopping. As initial probability for the occurrence of this event, admitted the value of $10^{-7}$, corresponding to the annual probability of rupture of a dam with good performance. In terms of sensitivity analysis, it was performed two alternatives, where it was estimated the influence of early detection probability of the flood. In the first situation, the probability of detection of the flood was low $(10 \%)$, due to the lack of instrumentation (Fig. 8) and in the second (Fig. 9), is the reverse situation, existing instrumentation system, the possibility of early detection of the flood was higher (90\%).

The final probabilities of the two alternatives were similar, resulting in, $6.2 \times 10^{-8}$ and $4.7 \times 10^{-8}$, which 


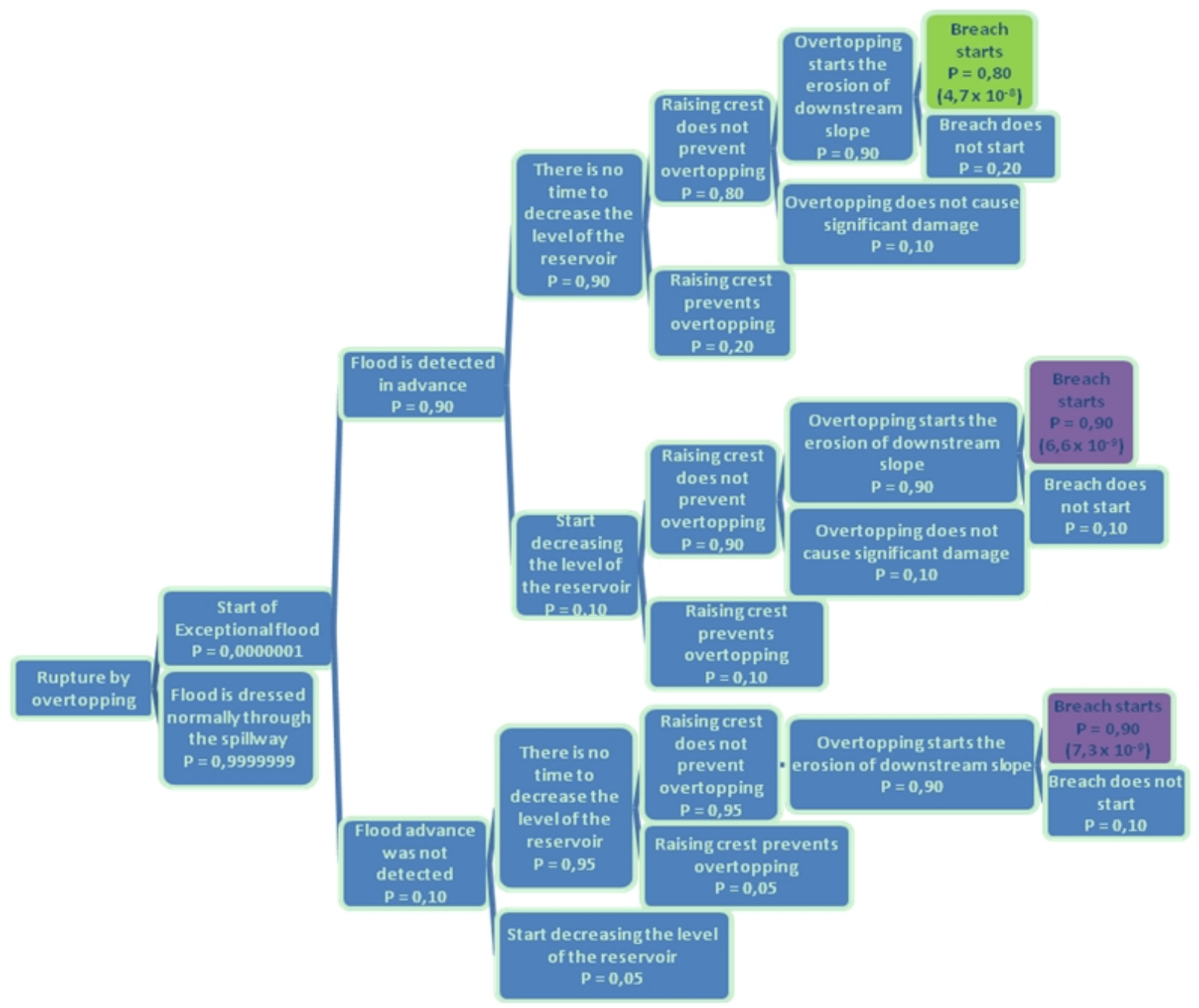

Fig. 8 Event Tree I-dam without instrumentation-erosion by overtopping (exceptional flood).

can be explained because there is no bottom spillway dams, and in the absence of the possibility of decreasing the level of the reservoir, annual probabilities of these events would be of the same order of magnitude. To the risk of overtopping, two more alternatives presented in Figs. 10 (Event Tree III) and 11 (Event Tree IV) were simulated, which simulated the influence of variation of the probability of detection of the flood in the event trees. In the first situation, the early detection of the flood would have just $1 \%$, while in the second, the probability of early detection of the flood would be $99 \%$. The final probabilities were similar to each other, i.e., $6.8 \times 10^{-8}$ and $6.2 \times 10^{-8}$, which were similar to the values obtained from the simulations of Figs. 8 and 9.

\subsection{Event Tree for Internal Erosion (Piping)}

The possibility of internal erosion was simulated in two alternatives: internal erosion through the landfill-foundation and internal erosion through soil-concrete interface. The cases of internal erosion through the foundation are presented in Figs. 12 (Event Tree V) and 13 (Event Tree VI). As initial probability for the development of internal erosion through the foundation, admitted the value of $1.9 \times 10^{-5}$ per person-year, corresponding to the world average of cases of internal erosion through the foundation according to statistical surveys of ANCOLD [31], as shown in Table 4. The value was divided by 10 for the second simulation, because it is a well designed dam, 


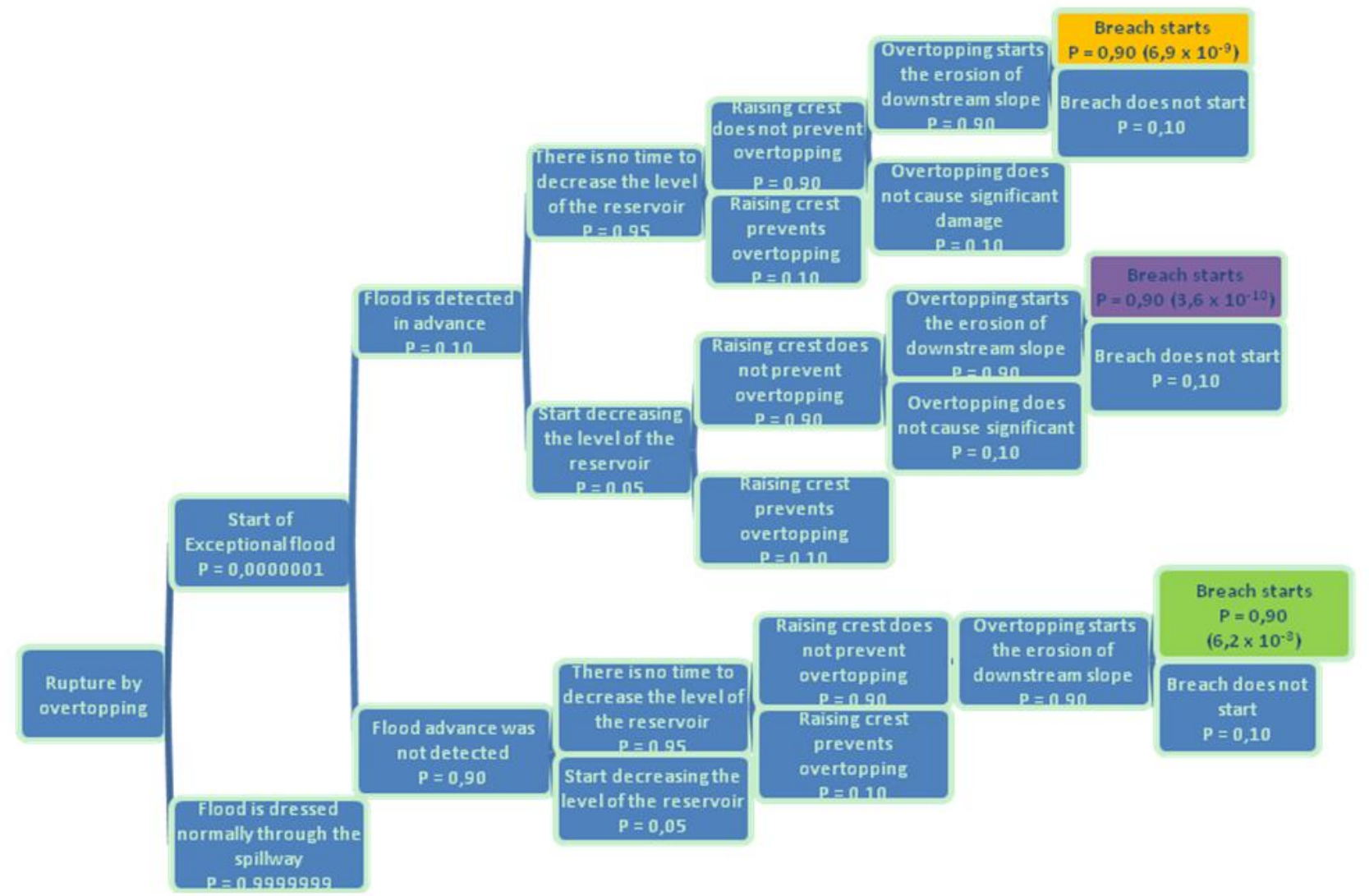

Fig. 9 Event Tree II-dam with instrumentation-erosion by overtopping (exceptional flood).

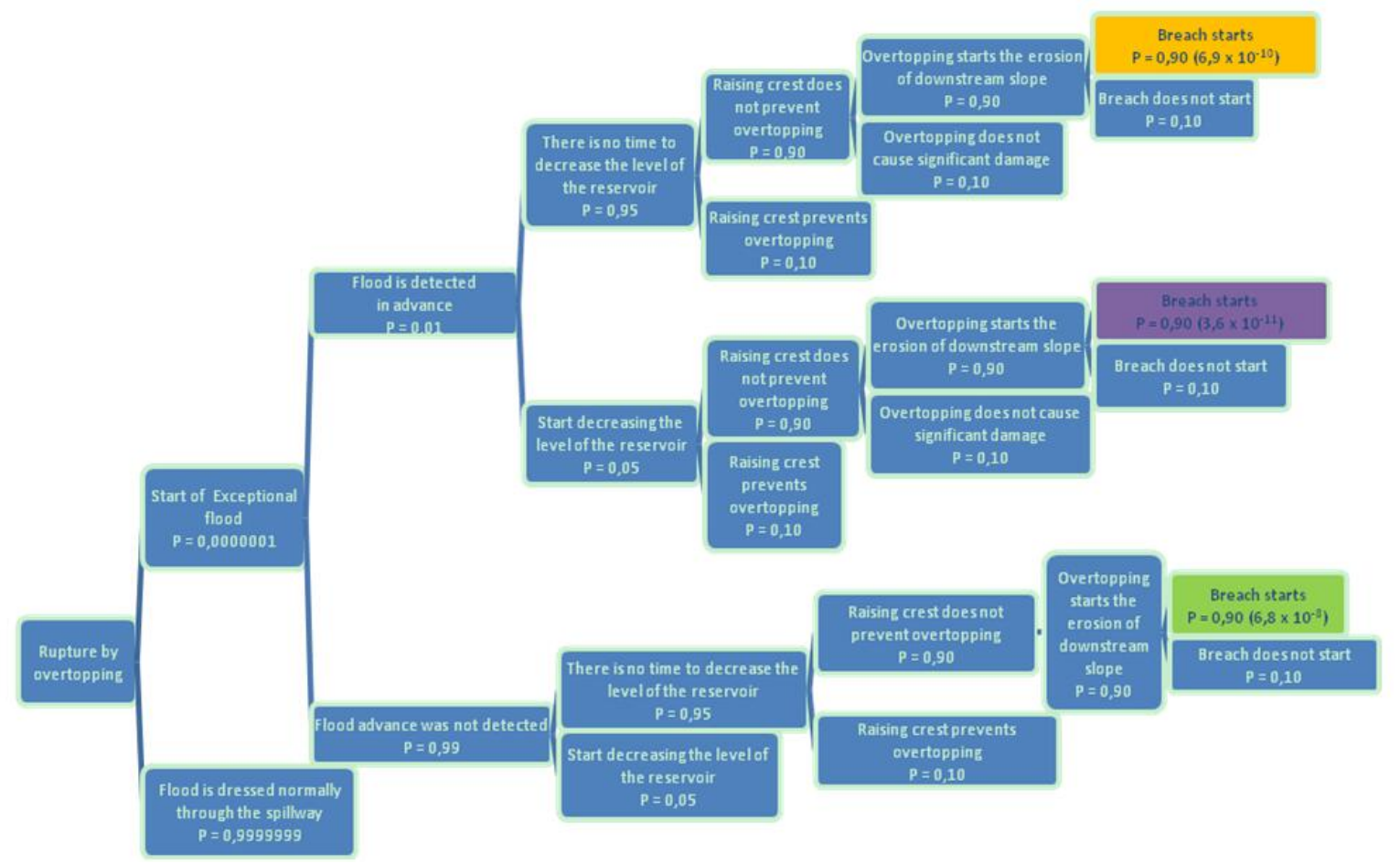

Fig. 10 Event Tree III-dam without instrumentation-erosion by overtopping (exceptional flood). 


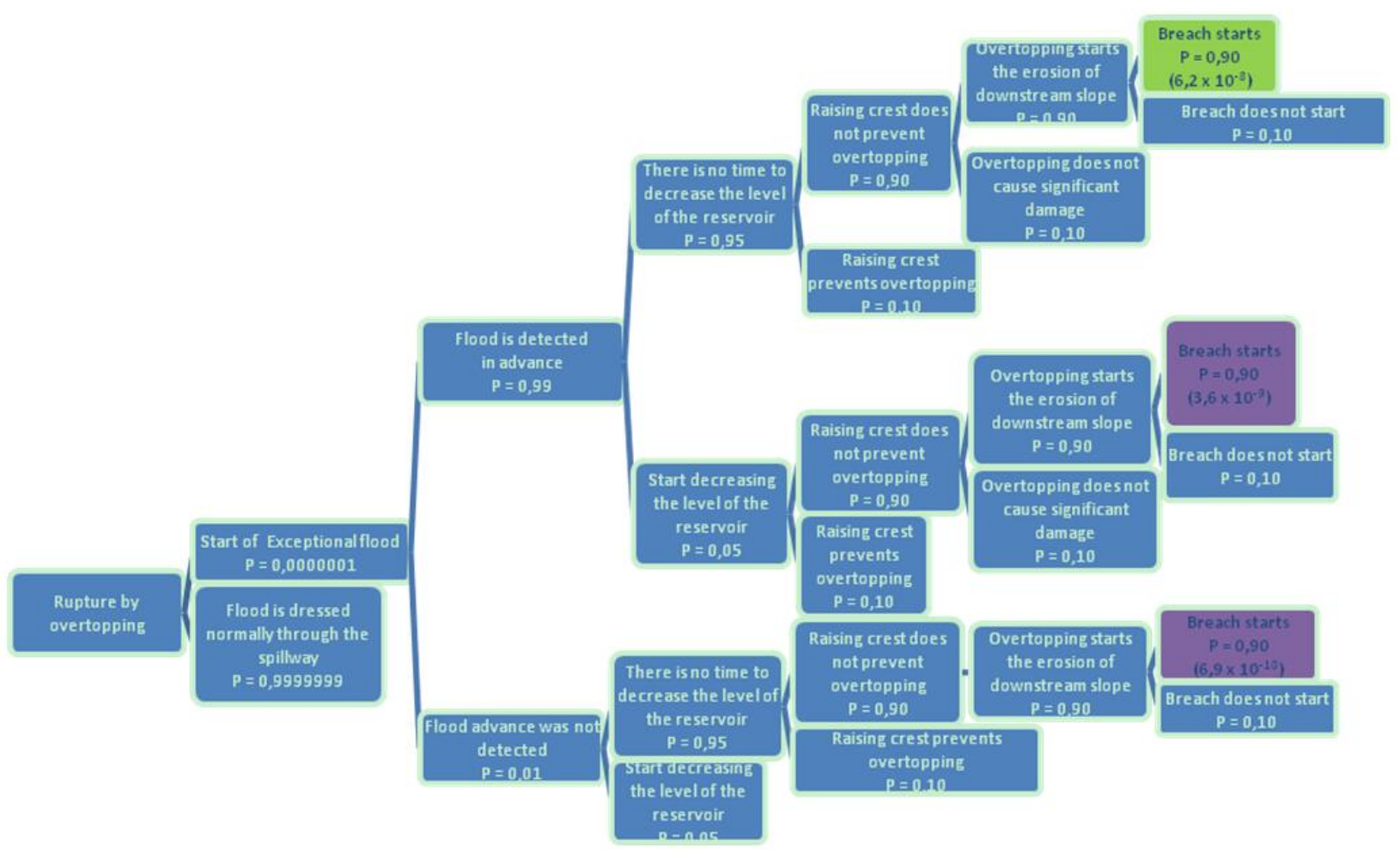

Fig. 11 Event Tree IV—dam with instrumentation-erosion by overtopping (exceptional flood).

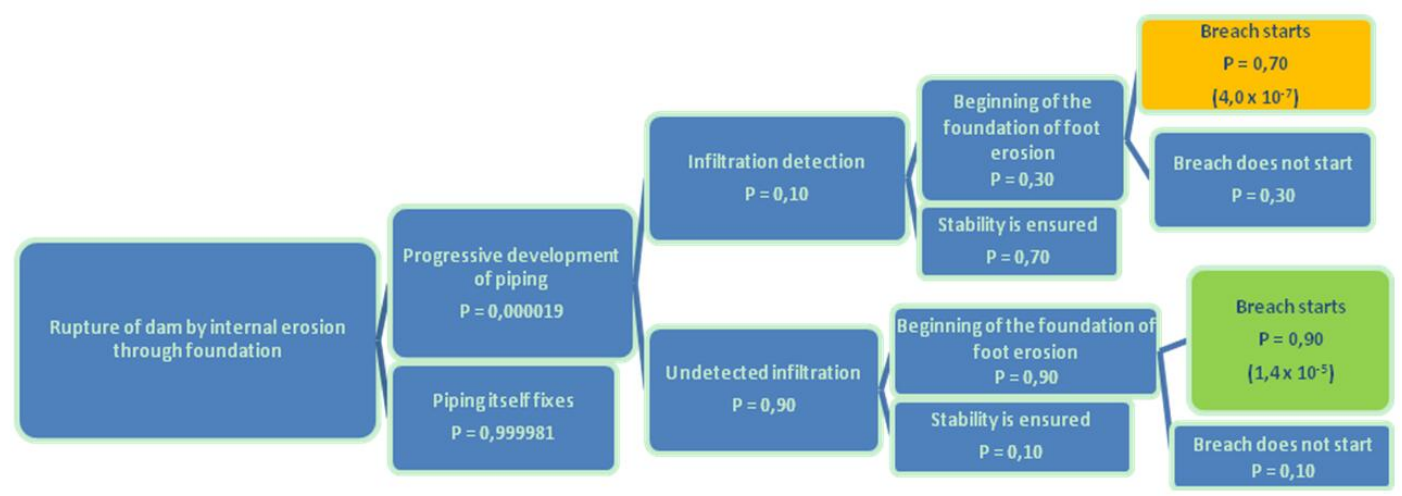

Fig. 12 Event Tree V-Internal erosion through foundation(dam with construction details not fully adequate).

Table 4 Annual probability of rupture of dam by internal erosion [31].

\begin{tabular}{ll}
\hline Type of internal erosion & Annual probability of rupture (per person per year) \\
\hline Piping through the landfill & $7.5 \times 10^{-5}$ \\
Piping through the foundation & $1.9 \times 10^{-5}$ \\
Piping through the landfill-foundation interface & $4.0 \times 10^{-5}$ \\
\hline
\end{tabular}

constructed and monitored properly, so as to be more secure than the world average. The dams analyzed, Simplicio and Batalha, fall into this second alternative.

In Figs. 12 and 13, investigated by the sensitivity analysis, the case of erosion of the downstream slope foot, caused by high leakage from internal erosion through the foundation, be respectively, $30 \%$ and $70 \%$. The resulting probabilities for these simulations were respectively, $1.4 \times 10^{-5}$ and $8.4 \times 10^{-7}$, with the highest probability related to the case that the infiltration would be of greater intensity, may cause erosion foot rockfill, with $90 \%$ probability. 
In Figs. 14 (Event Tree VII) and 15 (Event Tree VIII) are presented the event trees for the simulation of internal erosion through the concrete-soil compacted interface, assuming that the dam was designed and built under good project parameters, following the technical standards and legislation, in addition to having an adequate monitoring plan. The initial probability for the development of erosion through the concrete-soil interface was admitted as being $10 \%$ of the corresponding to the world average of erosion through this interface, i.e., $4.0 \times 10^{-6}$ per person year. This probability was admitted because, in this scenario, it was considered that the dam was very well designed and built, which would reduce the chance of a possible problem of piping, and would also have an adequate monitoring system, which would make possible the early detection of possible problems in the performance of the dam and its foundation.

According to the simulations, the highest probability was for the case of infiltration by internal erosion detected with $90 \%$ probability. In both simulations, respectively, with low and high probability of happening internal erosion, observed results of $3.2 \times$ $10^{-7}$ and $1.6 \times 10^{-6}$. The most critical value for this scenario of rupture, that is, piping through the soil-concrete interface, was $1.6 \times 10^{-6}$. Checking the two simulations performed to internal erosion by the foundation, where the most critical value was $1.4 \times 10^{-5}$, it is observed that the most critical scenario is for internal erosion by the foundation, thus obtaining similar results than the statistical surveys of the main causes of rupture of dams by Harrington [9], noting that the erosion of the foundation is the third biggest cause of rupture of dams, after the overtopping and leaks in

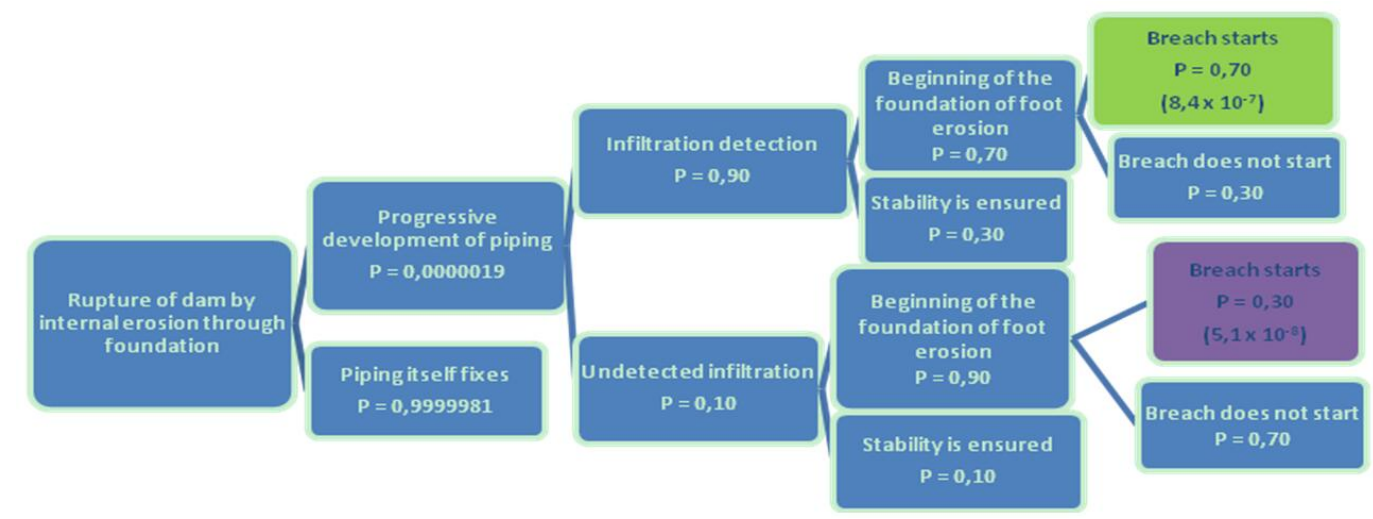

Fig. 13 Event Tree VI-internal erosion through foundation (well-designed dam, built and monitored properly).

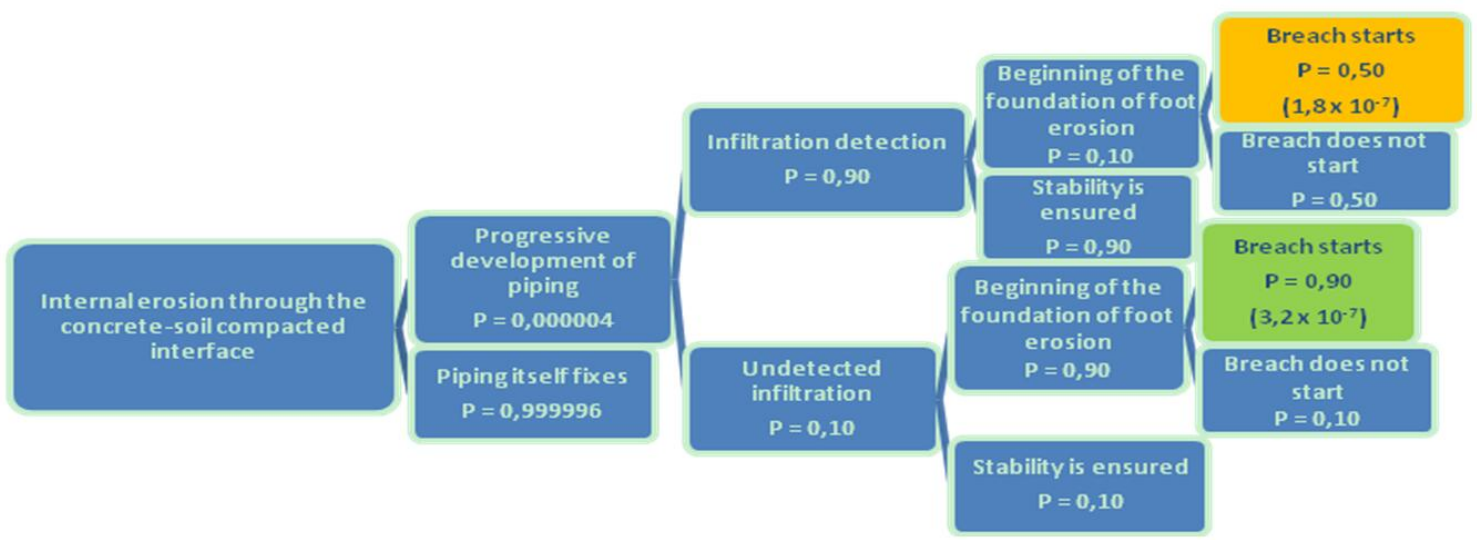

Fig. 14 Event Tree VII-internal erosion through the concrete-soil interface (simulation with low probability of happening to internal erosion). 


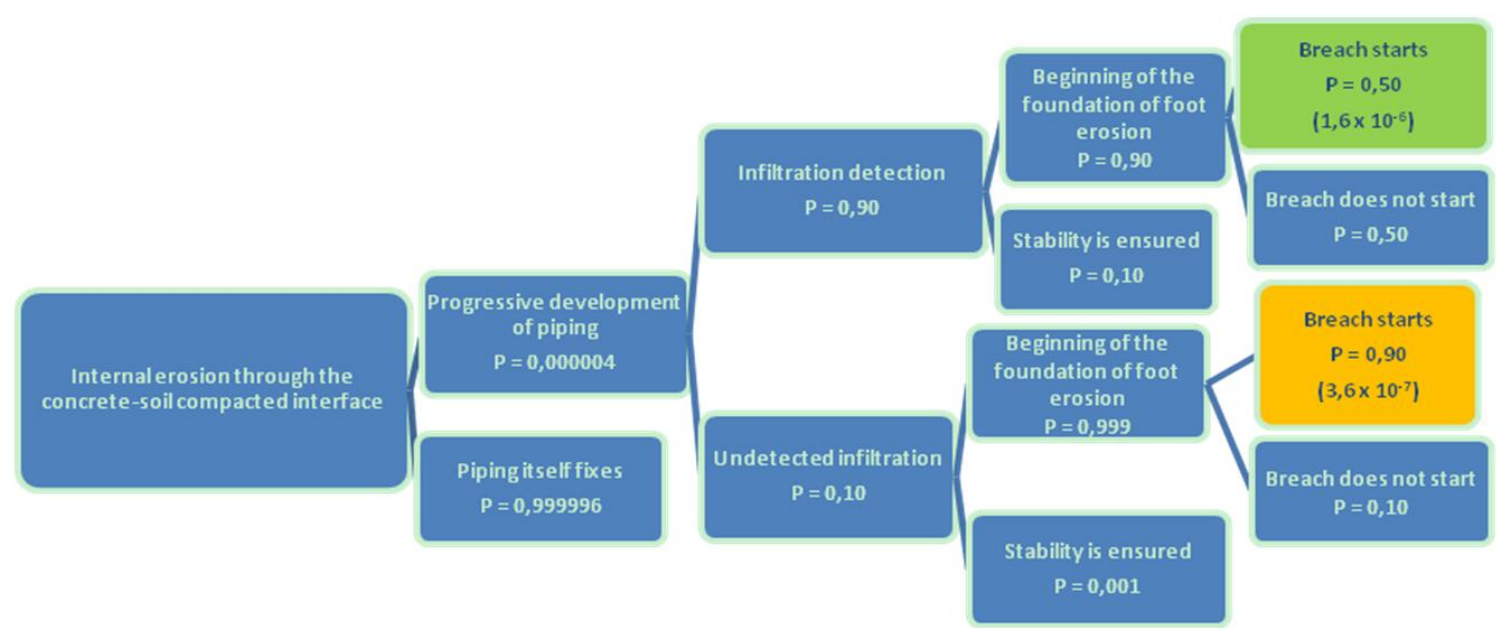

Fig. 15 Event Tree VIII-internal erosion through the concrete-soil interface (simulation with high probability of happening to internal erosion).

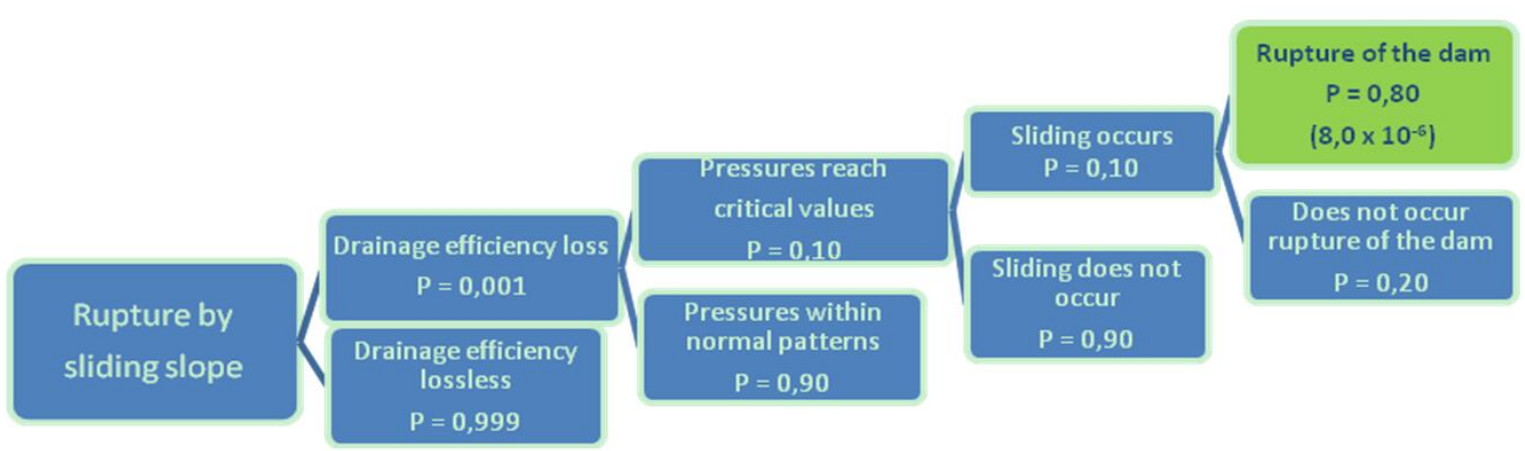

Fig. 16 Event Tree IX-sliding slope caused by inefficiency of the drainage system (simulation with greater probability).

pipes and massive dam.

\subsection{Event Trees for Sliding of Concrete Structures}

For simulation of sliding slope, two events were prepared, having as its objective the analysis of the influence of drainage system loss of efficiency in the foundation of concrete structures in order to ensure reducing pressures downstream drainage galleries, and ensure good conditions of stability for the concrete structures. The analysis of the Figs. 16 (Event Tree IX) and 17 (Event Tree X), can be observed that the results were $8.0 \times 10^{-6}$ and $7.0 \times 10^{-7}$, confirming that the concrete structures are much more stable and less subject to the risk of rupture than the earth-rockfill massifs. This observation stems essentially from the good features of foundation rock, that consists of gneiss.

In the simulation of Fig. 16, it was considered that the probability of drainage efficiency loss would be $0.1 \%$ and in the second simulation (Fig. 17), was set to $0.01 \%$ probability. The final results of these two simulations presented the values of $8.0 \times 10^{-6}$ and $7.0 \times$ $10^{-7}$, respectively, as rupture probability for a possible sliding slope.

\subsection{Analysis of the Event Tree Results}

For each simulation of risk, the annual probability corresponding to the highest value found through the event trees was computed, based on analyses of sensitivities carried out, according to Table 5. It is also represented the total probability, given by the sum of the probabilities of the various partial rupture scenarios analyzed, as well as performance of the dam is defined according to the definition of the level of acceptability of dam rupture (Table 3 ).

Observing Table 5, it appears that in relation to 


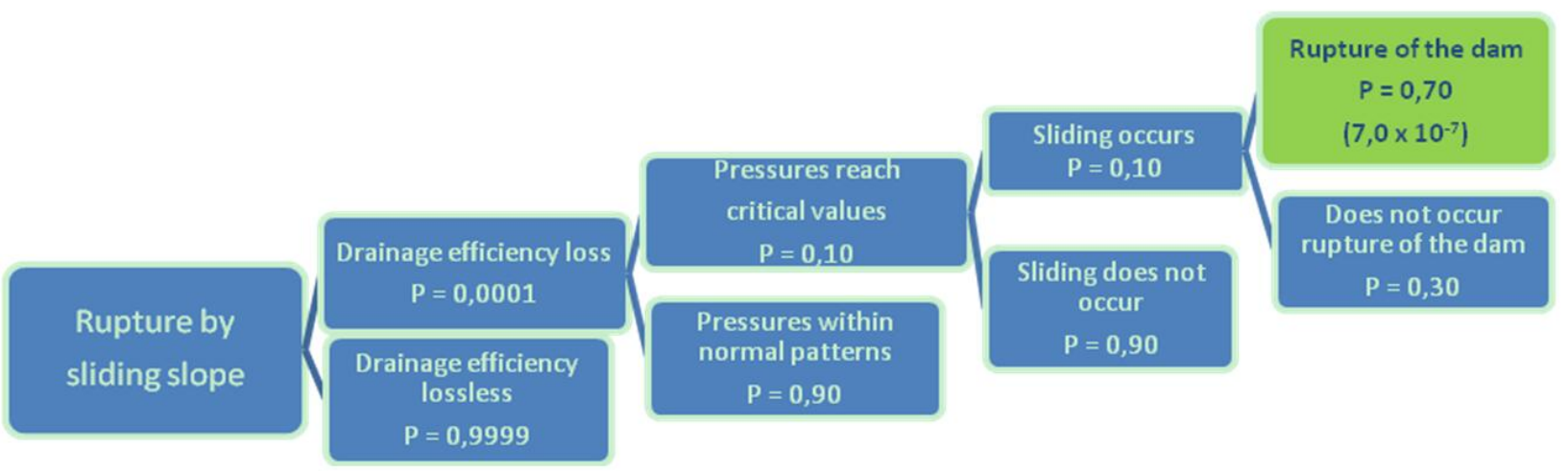

Fig. 17 Event Tree $\mathrm{X}$-sliding slope caused by inefficiency of the drainage system (simulation with lower probability).

Table 5 Summary of probabilities of estimated risk in the event trees.

\begin{tabular}{lllll}
\hline \multirow{2}{*}{ Type of risk } & \multicolumn{2}{c}{ Simulation I } & \multicolumn{2}{c}{ Simulation II } \\
\cline { 2 - 5 } & Annual probability & Performance of the dam & Annual probability & Performance of the dam \\
\hline Hydrologic (overtopping) & $6.2 \times 10^{-8}$ & Great & $4.7 \times 10^{-8}$ & Great \\
Internal erosion (foundation) & $1.4 \times 10^{-5}$ & Worrying & $8.4 \times 10^{-7}$ & Good \\
Internal erosion (soil-concrete & $3.2 \times 10^{-7}$ & Good & $1.6 \times 10^{-6}$ & Acceptable \\
interface) & $8.0 \times 10^{-6}$ & Acceptable & $7.0 \times 10^{-7}$ & Good \\
Sliding slope & $2.2 \times 10^{-5}$ & Worrying to acceptable & $3.2 \times 10^{-6}$ & Acceptable \\
\hline Total & & &
\end{tabular}

hydrological risk, the annual probabilities revealed a great performance of the dam, corroborating several authors, who argue that the risk of overtopping is more problematic when occurring in earth dams and not so much for concrete dams. The risks of sliding slope and internal erosion by concrete-soil interface are also in the range of acceptable to good for the performance of the dam. For the case of internal erosion through the foundation, the final probabilities were of $1.4 \times 10^{-5}$ per year, which classifies the risk as worrying. In terms of overall risk, resulting from the sum of the individual risks, was $2.2 \times 10^{-5}$ per person·year, classified as worrying to acceptable, that for a dam located near urban centres, is of course, not an acceptable risk.

In Alternative II, the scenarios analysed revealed annual probabilities in terms of overall risk, in the amount of $3.2 \times 10^{-6}$ per person'year, classified as acceptable performance.

The scenarios in Simulation I were a situation with the occurrence of major problems through a more pessimistic scenario, in relation to the projects, the construction and also did not have an efficient monitoring system. The second scenario was considered more optimistic, with effective and efficient building and design, and proper dam monitoring system. In this way, it can be concluded that negligence or inefficiency in any phase of the project, is in the feasibility study, design, construction, operation or maintenance and monitoring, can lead to greater risks. The projects analysed, Simplicio and Batalha, having rock masses of good quality, there is quality control of the compacted embankment, the internal drainage system of the dam and foundations is well designed and built and also includes a reliable dam monitoring system, fall into this second alternative of simulation.

\section{Conclusions}

This study had, as its main objectives, the identification, application and discussion of risk analysis in dams; evaluation of various methods of risk found worldwide; detailed analysis of two enterprises of Eletrobrás Furnas; application of FMECA and ETA in these dams and preparation and validation of the risk analysis method developed for the company.

The Eletrobrás Furnas dam risk analysis method was validated by experts interviewed for this study. This 
method was based on global methods of risk dams and taking into account the dam safety law existing in Brazil and is still suitable for the reality of the universe of the company's dams. However, the method can be used or adapted by other construction companies of hydropower plants.

Often, decisions on the allocation of maintenance resources are taken by the owners of dams in a non-technical environment, and the risk approach is widespread and generally easy to understand and acceptance by decision makers. The risk analysis should be seen as an improvement or supplement of the traditional practice of dam safety, and not as a replacement. Methods based on risk indexes and classification matrixes tend to an analysis more generally, with more generic descriptors. No matter that should be used only in a preliminary risk assessment, such techniques are very useful for dam classification and should constitute an integral part of any dam safety management program.

Unfortunately, there is not yet a historical basis and comprehensive information of the dams, not being possible to perform the comparative benchmarks for assessing external risks with a larger number of dams. Therefore, it is understood that the Eletrobrás Furnas dam risk method by constituting a natural evolution of predecessors methods and the extent to which it can be used, is a suitable tool in order to identify the greatest risks dams.

An integrated methodology of evaluation of dams in phases, starting from more general methods for the more structured, can be very useful, considering the time and costs involved in development more complex risk analysis. The initial phase, with the aid of the preliminary analysis method best suited to the universe of dams under observation, allows the identification of the structures that are at higher risk within the portfolio. The second phase of evaluation, applied to the identified dams, tends to address the weaknesses of the implementation of the previous step. In this sense, FMECA was proved to be a very suitable method for the general knowledge of system rupture characteristics, getting a comprehensive risk analysis, and further detailed by the system.

Aiming at a more complete analysis, can be of great value a third step with the most rigorous methods, such as by ETA. However, considering the complexity of failure mechanisms in dams, and the difficulty of quantifying probabilities of dam failure on a scientific basis, it is not always possible to obtain a consistent theoretical basis for the construction of the trees. In fact, considering the methods described in this study, with its advantages and limitations associated, it can be concluded that there is no single method applicable to any study of risks in dams. Thus, analysis combined in steps is very important in this regard.

The dams analyzed present low probability of rupture and high consequence (in case of Simplicio), intrinsic characteristic of large dams in the Brazilian electricity sector given the size of the structures and the large volumes of dammed water. Generally, the structures are well constructed, operated, and maintained. In the methods in which there is reference values for risk assessment, it can be inferred that the identified dam risks are acceptable.

Finally, it appears from this study, the importance of minimizing the probability of finding unexpected conditions of a critical nature, through the planning of geological and geotechnical research, hydrological-hydraulics investigation, civil works, feasibility and projects in more than one step, and depending on the features of construction and operation of the dam. In addition, it is important to select the construction method depending on geological and geotechnical conditions, using risk analysis and decision-making and identifying the risks and strategies for its controls, at the beginning of the project. It is also important to undertake periodic inspection, annually or every 6 months, for dam safety assessment. Another aspect to consider is the establishment of a dam safety culture between owners, designers and builders, because no construction project 
is risk-free, so these can be managed, minimized, shared, transferred or accepted, but never ignored.

\section{References}

[1] CBDB (Comitê Brasileiro de Barragens). 1999. Núcleo Regional de São Paulo, Guia Básico de Segurança de Barragens. São Paulo: CBDB. (in Portuguese)

[2] Serafim, J. L. 1981. "Safety of Dams Judged from Failures." Water Power and Dam Construction 33 (12): $32-5$.

[3] ICOLD (International Commission on Large Dams). 1983. Deterioration of Dams and Reservoirs. Report prepared by a team of Portuguese engineers of the Laboratório Nacional de Engenharia Civil, LNEC, Lisboa, Portugal.

[4] Brasil, L. S. S. 2005. "Utilização de Modelagens uni e Bidirecional para a Propagação de onda de Cheia Proveniente de Ruptura Hipotética de Barragem: Estudode caso Barragem de Riode Pedras-MG (Use of Modeling Originating from Hypothetical Dam Break: Pedras-MG River Dam Case Study)." Dissertação de mestrado, Universidade Federal de Minas Gerais, Programa de Pós-Graduação em Saneamento, Meio-Ambiente e Recursos Hídricos, Belo Horizonte-MG. (in Portuguese)

[5] Viseu, T., and Martins, R. 1997. "Optimização de Recursos nas Acções de Segurança de Barragens (Resource Optimization in Dam Safety Actions)." Presented at III Simpósio de Hidráulica e Recursos Hídricos dos Países de Língua Oficial Portuguesa (SILUSBA), Maputo, Moçambique. (in Portuguese)

[6] ICOLD. 2005. Risk Assessment in Dam Safety Management: A Reconnaissance of Benefits, Methods and Current Applications. Paris: ICOLD.

[7] Caldeira, L. M. M. S. 2008. Análises de Riscos em Geotecnia: Aplicação a Barragens de Aterro (Risk Analysis in Geotechnical Engineering: Application to Embankment Dams). Lisboa: LNEC. (in Portuguese)

[8] Hartford, D. N. D., and Baecher, G. B. 2004. Risk and Uncertainty in Dam Safety. London: Thomas Telford Publishing.

[9] Harrington, B. 2001. Dam Break Analysis \& Hazard Classifications. Maryland: Maryland Dam Safety.

[10] CNPGB (Comissão Nacional Portuguesa das Grandes Barragens). 2005. Grupo de Trabalho de Análise de Riscos em Barragens (Working Group on Risk Analysis for Dams). 1st progress report of CNPGB. Accessed May 17, 2015. http://www.apambiente.pt/index.php. (in Portuguese)

[11] Paolina, R., Appendido, M., Baldovin, E., Berra, M., Bianchini, A., Carabelli, E., Posta, U., and Vielmo, I. 1991. "Deterioration Problems for Concrete and Masonry Dams in Italy." In 17. ICOLD Congress, Vol. II, 785-815.

[12] Aven, T. 2012. Foundations of Risk Analysis. 2nd ed. Chichester, West Sussex, United Kingdom: John Wiley and Sons.

[13] Ayyub, B. M. 2014. Risk Analysis in Engineering and Economics. 2nd ed. University of Maryland, College Park: USA CRC Press, Taylor and Francis Group.

[14] Kearnes, M. B., Kauser, F. R., and Lane, S. N. 2012. Critical Risk Research: Practices, Politics and Ethics. New Jersey: John Wiley.

[15] Bowles, D. S. 2010. "Dam Safety Risk Management for Hydroelectric Projects." Presented at International Conference on Hydropower Projects in Portugal: A New Cycle, Porto. Accessed May 17, 2015. http://uwrl.usu.edu/people/faculty/bowles.html.

[16] HSE (Health and Safety Executive). 2001. Reducing Risks, Protecting People. Norwich: Her Majesty's Stationery Office.

[17] Morris, M., Samuels, P., and Elliott, C. 1999. "Risk and Reservoirs in the UK." In CADAM Meeting, Zaragoza, Spain, 441-50.

[18] Australian National Committee on Large Dams. 1994. Guidelines on Risk Assessment. ANCOLD Working Group.

[19] Fontenelle, A. S., Figueiredo, N. N., and Vieira, V. V. P. 2002. "Dam Safety Program in Ceará State in Brazil." Presented at Anais do International Congress On Conservation And Rehabilitation On Dams, Madrid, Espanha.

[20] Lafitte, R. 1996. "Classes of Risk for Dams." International Journal on Hydropower and Dams 3 (6): 59-66.

[21] Menescal, R. de A., Vieira, V. de P. P. B., and Oliveira, S.K.F. 2001. "Terminologia para a Análise de Risco e Segurança de Barragens (Terminology for Risk Analysis and Safety of Dams)." In Seminário Nacional de Grandes Barragens (SNGB), 24. Fortaleza, CE, 31-53. (in Portuguese)

[22] Kuperman, S. C., Re, G., Ferreira, W. V. F., Tung, W. S., Vasconselos, S. E., Zúniga, J. E. V., and Rabello, M. 2001. "Análise de Risco e Metodologia de Tomada de Decisões para Barragens: Evolução do Sistema Empregado pela Sabesp." In Seminário Nacional de Grandes Barragens (SNGB), Fortaleza, CE. XXIV Seminário Nacional de Grandes Barragens-Anais, Rio de Janeiro: CBDB-Comitê Brasileiro de Grandes Barragens, 535-48.

[23] Fusaro, T. C. 2003. "Metodologia de Classificação de Barragens Baseada no Risco (Dams Rating Methodology Risk Based)." Presented at Seminário Nacional de Grandes Barragens (SNGB), Salvador, BA. XXV Seminário Nacional de Grandes Barragens-Anais. (in Portuguese) 
[24] CNRH (Conselho Nacional de Recursos Hídricos. 2012. Conjunto de Normas Legais: Recursos Hidricos (Set of Legal Norms: Water Resources). 8th ed. Brasilia: Ministério do Meio Ambiente. (in Portuguese)

[25] Pimenta, M. L. B. 2009. Abordagens de Riscos em Barragens de Aterro (Risk Approaches Embankment Dams). Lisboa: LNEC. (in Portuguese)

[26] ICOLD. 2008. 80 Years: Dams for Human Sustainable Development. Paris: CIGB/ICOLD.

[27] Bowles, D. S. 2001. "Advances in the Practice and Use of Portfolio Risk Assessment." In ANCOLD 2000, Conference on Dams, Cairns, Proceedings of the Australian Committee on Large Dams Annual Meeting-Bulletin 117, 21-32.

[28] Portes, A. M. C. 2013. "Avaliação da Disposição de
Rejeitos de Minério de Ferro nas Consistências Polpa e Torta." Dissertação de Mestrado em Geotecnia e Transportes, Escola de Engenharia, Universidade Federal de Minas Gerais, Belo Horizonte.

[29] Espósito, T., and Palmier, L. R. 2013. "Application of Risk Analysis Methods on Tailings Dams." Soils and Rocks, São Paulo 36 (1): 97-117.

[30] Silveira, J. F. A. 1999. “A Análise de Risco Aplicada a Segurança de Barragens (Applied Risk Analysis to Dam Safety)." Revista Brasileira de Engenharia, ed. especial, nov. 1999, 1-42. (in Portuguese)

[31] Australian National Committee on Large Dams-ANCOLD. 2003. Guidelines on Risk Assessment. Sydney: Australian National Committee on Large Dams Inc. 